\title{
AIDS drug row embroils health minister
}

[CAPE TOWN] South Africa's health minister, Nkosazana Zuma, an anti-AIDS campaigner who has enthusiastically supported a controversial AIDS drug, has come under fire for failing to distance herself from the criticisms of two separate bodies about unauthorized clinical trials of the drug.

The controversy over the effectiveness of the drug, and the conditions under which trials with it were carried out, threatens to develop into a serious conflict between South Africa's fledgling democratic government and the Medicines Control Council, the Gauteng Department of Health and the University of Pretoria.

Last month, the Medicines Control Council, the country's drug regulatory authority, suspended clinical trials of the drug, Virodene, which was developed by three researchers at the University of Pretoria's department of cardio-thoracic surgery. The drug's active ingredient is a highly toxic industrial solvent, dimethylformamide.

The researchers had proceeded with the trials without obtaining clearance from the council, and after their application to the university's ethics committee to conduct trials had been rejected (see Nature 385, 474; 1997). Normally applications have to be vetted by both bodies before trials can proceed.

The medicines council is concerned pri- marily because the drug's active ingredient can cause irreversible and fatal liver damage, and has also been linked with the development of cancer in humans and experimental animals. The trials have been suspended until aspects of the drug's safety, weaknesses in the trial design, and the evaluation of results obtained so far, have been resolved. But several patients are claimed to be in remission as a result of receiving the drug.

Council chairman Peter Folb says that the clinical trials were designed in such a way that they could not be properly analysed statistically, and contained inadequate accounts of the patients treated. There had also been no validation of assays performed.

"The fact that the normal requirements for conducting a clinical trial were not met is unacceptable and potentially dangerous," says Folb. He adds that safety issues need to be resolved before any further work can be considered, and before patients who have already received Virodene are further exposed to the drug.

It is up to the University of Pretoria and the provincial health authority of Gauteng, which jointly employ two of the three researchers, to decide whether to initiate disciplinary procedures against them over the earlier trials.

A joint committee appointed by the two

\section{'Data network threatens patient privacy'}

[PARIS] France's data-protection authority and the council that regulates the medical profession have warned that a planned national computer network for the management of patient information threatens individual liberty and privacy, medical confidentiality and the professional independence of physicians.

Under a law passed last year, all physicians must equip themselves before 1999 with computers capable of transmitting patient information to the state health-insurance scheme. Although the main aim is to introduce savings and reduce the social-security deficit, the network will also improve diagnosis by allowing online consultation of databases .

But the availability of patient information also represents a goldmine for drugs companies interested in prescription practices. The sensitive data also risk being exploited by insurance companies, banks and employers.

In a statement issued in Paris two weeks ago, the Commission Nationale de L'Informatique et des Libertés (CNIL) which oversees the 1978 data-protection act - says commercial exploitation of data should be banned. Both CNIL and the medical council, the Conseil National de l'Ordre des Médecins (CNOM), also recommended that all data submitted to the network should be processed to ensure the anonymity of both patients and physicians. The CNIL said that connections between the network and the Internet should be banned.

Olivier Dubois, secretary general of CNOM, says that its recommendations almost identical to those of CNIL - are aimed at protecting basic human rights while preserving researchers' access to data.

Under the recommendations, the use of computerized data would require contracts specifying the aim of a project in terms of public health or medical research. These would have to be approved by the local ethics boards established by the 1988 Huriet law governing clinical trials. Following approval, researchers would not need to seek the consent of individual patients, although patients would have the right to deny use of information about them.

Ethics boards would be authorized to waive the requirement of anonymity in cases where it was essential to the goals of the research, as in chronic diseases such as AIDS and cancer where there may be a need to track individual patients Declan Butier authorities, which reported last week, has been even more critical of the researchers' infringements than the Medicines Control Council was. Chaired by the university's professor of genetics, Henk Huisamens, the committee found that the company Cryptopreservation Technologies, which has patented the drug, appears to have an unauthorized association with both the university and the researchers' department.

It found that the company's involvement "might have created a potential conflict of interest that would not have been to the advantage of open-ended research". One of the three researchers, perfusion technologist Olga Visser, was discharged from the department of cardio-thoracic surgery for medical reasons last July, and is now joint manager of this company, together with her husband.

The company has issued a statement saying that nothing will stop its research from going forward. The group says that a "top pharmaceutical research concern" will handle the next trial.

Zuma, meanwhile, has denied claims that she authorized the trials personally, saying she merely "encouraged" the three scientists to continue their work, of which she has been aware since last July. She claims not to have checked that they had followed the standard procedures as she had assumed they had done so.

She also appears reluctant to criticize the researchers' infringement of the conventional procedures intended to protect the scientific and ethical integrity of trials of new drugs. At a press conference last month she emphasized that side-effects of drugs had to be weighed against their benefits, adding that one patient had been on the drug for five months without displaying any apparent side-effects.

Zuma's passionate commitment to combating AIDS, which is now a serious problem in South Africa, stirred controversy last year when she approved R14 million (US $\$ 3$ million) funding for an educational play, Sarafi$n a$, which turned out to be a scam. The play was intended to raise awareness about the disease among the country's poorer communities, but it emerged that funding was being squandered on lavish payments to its producer and actors. A controversy developed both about the play's effectiveness in achieving its stated objective, and the manner in which its funding was approved.

The Virodene controversy has resulted in renewed calls for Zuma's resignation, both from the official opposition, the National Party, and the smaller Democratic Party. But President Nelson Mandela backed her strongly last year, praising her exceptional competence as a minister, and is likely to do so again.

MichaelCherry 